\title{
A pursuit of intellectual equity in an uneven world
}

HANAFI, Sari; YI, Chin-Chun (Eds.). Sociologies in dialogue. Newcastle upon Tyne, UK: Sage, 2020.

Ana Cristina Collares (https://orcid.org/0000-0002-7326-4491), Departamento de Sociologia, Universidade de Brasília, Brasília, DF, Brasil'.

"The main currents associated with notions of global sociology, [...] typically encompass 'an active, open, mutually beneficial and equal interaction between sociologists from different locations, countries and cultures, in their joint efforts to understand, explain and improve the social world'."

(Sorokin 2016: 43, quoted in Wotherspoon, p. 246).
Recebido: 11.05.21 Aprovado: 21.06.21

\author{
I. Ana Cristina \\ Collares é professora \\ do Departamento \\ de Sociologia e \\ do Programa de \\ Pós-Graduação em \\ Sociologia (PPGSOL/ \\ UnB) da Universidade \\ de Brasília, Brasília, \\ DF, Brasil. \\ <anacoll47@gmail. \\ com>.
}

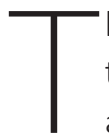
he nations' boundaries as we know them have never been challenged as they are right now. Along with the increasing flow of migrants from Africa and the Middle East provoking clashes between liberals and conservatives in almost every European country - as well as cultural and religious estrangement between established citizens and newcomers - there is immense pressure from asylum-seekers at the United States' southern border and even in countries like Brazil, which recently became an important migrant destination after a hiatus of almost 100 years. Conversely, border controls in almost every country have become stricter since last year and international traveling has come to a near halt due to the COVID19 pandemic (or syndemic, as some have come to classify it (Horton, 2020). In this scenario, inequality, violence, political polarization, fake news, and resistance to scientific knowledge are becoming common place. The current state of affairs makes a book like Sociologies in dialogue a necessary and welcome addition to every sociologists' reading list.

Drawing from writings and presentations from the fourth ISA Conference of the Councils of National Associations held in 2017, the book encompasses articles from a wide range of countries with contents spanning across issues such as the history, 
current status, and local challenges of practicing sociology nowadays at all levels. The key promise of this volume - which the title implies - is to place widely diverse sociological perspectives from the global North and South in dialogue, while also analyzing and dissecting the push for 'internationalization' within those contexts. The book fulfills such promise by promoting "meaningful dialogues" across diverse points of view (Abraham, Foreword), at the same time challenging traditional perspectives, hierarchies, and epistemologies. Through the narratives of each author, or groups of authors, we realize the tremendous cultural, political, and societal changes that have shaken prior sociological paradigms.

One of the strengths of Sociologies in dialogue is that most authors envision Sociology as going beyond atomized empirical research and towards its "original vocation" for producing broad theories and devising connections between agents and structures within the social world. While not diminishing the role or importance of empirical research, the contributors push sociologists towards producing new theoretical frames and structures to understand social (or human) relations, ones that encompass and clarify current conflicts. There is also an implicit defense of public sociology - or the active involvement of sociologists in the enterprise of raising awareness to potential or actual sources of violence and promoting new pathways for social change. This is a necessary sociological enterprise, since

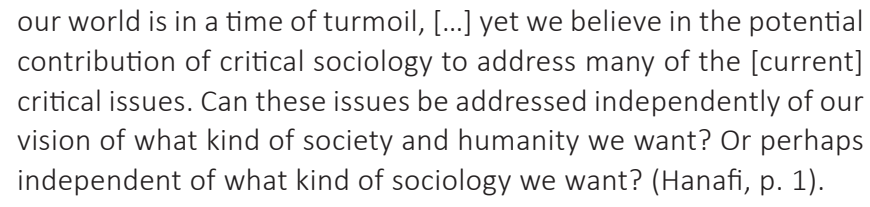

In the introduction, Sari Hanafi (p. 2) highlights "three necessary conditions for sociologies to be in dialogue": first, a deconstruction of the binary logic of antagonistic categories such as tradition and modernity, north and south, religious and secular, empirical and normative sociology; second, the necessity of reaching 'a cross-cultural consensus on universal concepts'; and third, the need to connect sociological knowledge across borders. To achieve these, Sociologies in dialogue is divided into five parts: "Trends in internationalization of sociology (North-South and South-South)"; "Emerging local sociologies"; "Sociology in (post-)authoritarian context"; "When sociology becomes public"; and "Hurdles for the dialogue: challenges of the institutionalization of sociology". Most essays raise overspread and general concerns connected to the relation between the global South and North, common across book parts, which I will attempt to summarize in two main topics - the push for internationalization of science and the need to create or to accept new epistemologies - and some final considerations on how the book reinforces our ability to look critically at our own context. 


\section{Pathways to internationalization}

One of the book's core issues is the 'internationalization of sociology'. Essays in Part I point to a ubiquitous pressure upon local scholars to gain more international prominence and to increase publishing and research collaboration across borders, in every direction: North-North, South-South and South-North. However, almost all of them highlight the risk an "internationalization" conceived from a centralized, global North, colonial or dominant perspective, whereby the ideal model of social research would entail performing standardized empirical studies which follow certain "certified" methodologies, always written in English. The authors discuss how this model of internationalization places countries from the global South in a subordinate position relative to North America and western Europe, biasing knowledge about local social interactions, conflicts and power games.

Global inequalities in the diffusion of knowledge, including but not limited to sociological research, can be partially related to the use of bibliometrics to assess the quality of publications. International rankings of journals and scientific papers - based on, for instance, counting the number of citations of each article in other publications - generate a vicious cycle in which a limited number of journals are always atop of the ranks. Writing in English thus becomes an inescapable requisite for reaching a wider international audience, and a certain number of journals from the global North become the "certified" publication venues if one wants to be cited internationally (Nobrega, 2018).

In chapter 2, for instance, Paola Borgna describes how Italian universities proactively engage as agents of globalization, imposing rules and directing incentives to international publication and cooperation. However, in doing so they are forced to or subjected to adopting assessment policies for measuring the quality of research and the quality of teaching based on these centralized indexes, lessening their ability of focusing on subjects and methods which could be more adequate to promote local development and internal circulation of locally meaningful academic production. Borgna refers to this "internationalized sociology" as Globish sociology, that is, a Global sociology written in English and based on centralized standards.

Along those lines, Anna Wesseley (chapter 5) sees the push for internationalization as a lost opportunity for 'Central European countries' ${ }^{1}$ to enrich sociological knowledge by employing the "specific local social knowledge and sociological perspective developed in Central Europe" (p. 65). Driving on Mannheim's notion that knowledge is always "either locally or socially restricted, or 'existentially bond"" (p. 67), she goes on to say that "all knowledge is situated, reflecting the particular
1. Wessely chooses this denomination "Central European" purposefully, stating that "The countries between Germany to the west and Ukraine, Romania and Bulgaria to the east insist on their being distinguished from Eastern Europe and demand to be regarded as constituting the region of Central Europe, the borders of which are, of course, uncertain and thus always open to debate" (Wesseley, Footnote 1). 
conditions of its production" (p. 67). So, thinking specifically of the humanities, she questions "whether it is possible at all for any form of knowledge to be global" ( $p$. 66). Such experiences as seen by Hungary and other Central European countries, Wesseley claims, would be particularly enlightening to scholars globally because they portray the unique position of these countries, between the push to be part of the West and the cultural and political domination of the Soviet Union. This unique perspective gets lost when all countries adopt western standards so as to promote international dialogues.

Several of the essays in this collection, especially the nine essays that make Parts II "Emerging new local sociologies" and III "Sociology in (Post-) Authoritarian Context", suggest some new languages to translate social experiences to a common ground. A good example of the production of new languages of translation for sociology in the global South can be also found in Martins and Dwyer's essay (Part I, Chapter 3) narrating knowledge exchanges among the BRICS' countries in recent years.

\section{Local versus global experiences}

Using an optimistic tone when talking about the internationalization of sociology, Tom Dwyer and Carlos Benedito Martins (chapter 3) describe the efforts toward internationalization of Brazilian sociology as part of a drive for the creation of a meaningful dialogue among the BRICS, following the South-South axis of international collaboration. The authors show the relevance of language of publication for directing choices about where to publish, but not in the sense of pushing scholars to publish in English: rather, Brazilian sociologists published in languages which have closer roots to Portuguese, Brazilian's mother language. Nevertheless, consistent with the criticism of a centralized notion of "internationalization", this translated into very few Brazilian researchers publishing in internationally indexed journals, thereby limiting the reach of research produced by these scholars.

However, the experience of internationalizing through the connection with other countries from the global South, namely China, Russia and India (and eventually South Africa), all belonging to the group named BRICS, demonstrates the possibility of an enduring, non-hierarchical collaboration which could enrich sociological perspectives through mutual attempts at translation.

Further obstacles related to creating global sociological dialogues are critically pointed out by other essays. In chapter 6, for instance, Denis Erasga confronts a nativist "Filipino Sociology" to a possible global Sociology. The latter would not be 
able to fully express local conceptualizations since it is embedded into a tendency to modernocentrism, "a tendency to reckon modernity as the epistemological axis of every possible debate" (p. 81) and which "ushers a form of "palliative indigenization' where unbidden respect for local realities is afforded but not without an itch to patronize". (p. 82) On a different tone, Roberto Briceño-León proposes, in chapter 7, the concept of a "Mestizo" Sociology of Latin America, which cannot deny either its colonized or its indigenous or native origins, and needs to find "the right combination to respond to social miscegenation" (p. 98): "We are not Europeans, we are not Indians, but a middle species between the aborigines and the Spaniards" (Simón Bolivar, 1966:164 quoted by León, p. 98). Briceño-León describes the use of sociological theories taken as "universal" to interpret local realities in Latin American contexts (in the absence of self-developed theoretical traditions) as misplaced. In fact, these "universal theories" are the product of specific societies and fit much better into their own national interpretations. Léon describes how a hybridization between these "universal" theories and particular concepts has not succeeded, rather pressing maladapted categories into specific or singular contexts.

The candid narratives about the historical development and the current state of sociology in the remaining essays of parts II and III are "food for thought" to the reader, providing an insider's look into perspectives and contexts not usually discussed in international venues. They bring to mind, for instance, the wide gaps created between internationalized scholars (those who escaped from authoritarian regimes to live and work abroad) of countries such as Syria, Palestine and Taiwan, and those who remain struggling on the ground to develop a meaningful science and translate their contexts and views to a wider audience. In the case of these countries, a sociologist's struggle is not to create a national self-identity separated from historical colonial domination: it is a desperate attempt to produce knowledge while under civil unrest and/or political and cultural pressure.

In Taiwan, for instance, the development of sociology is entwined with the process of democratization and creation of a national identity for the country, dating back to the 1950's. Sociologists are split between, on one side, a push towards more interaction with the international community - which means using English as the language for communication and traditional methodologies such as surveys - and a push for "indigenization" on the other side, seeking forms of "academic subjectivity" linked to Chinese sociology and the publication of papers in Chinese. On chapter 12, Kheder Zakaria highlights these internal divisions in the local development of sociology while poignantly narrating the developments of his own career parallel to the advances of sociological science in Syria. As it went on, he describes Syria's political and social climate at the time as a "protracted authoritarianism", a brutalizing 
process which "starts with the destruction of social ties and solidarity, leading to the exclusion of groups from the national community and enabling an everyday barbarism against them that eventually becomes generalized across society." (p.177) As a consequence, many scholars left Syria but kept studying Syrian society and its "internally displaced people", while also "focusing primarily on political sociology and the refugee communities abroad.

Among these essays analyzing little-discussed fields of contestation from the point of view of the development of sociology, the process in Azerbaijan draws attention because of its peculiarities. The reconstruction of its ethnocultural identity, narrated in Chapter 13 (Guliyev), is described as influenced by a national ideal of tolerance towards interaction between different cultures within the common homeland. With its peculiar acceptance of the country's multicultural origins, its sociology generates unique frames that allow for a particular the understanding of issues such as ethnic conflicts. In stark contrast to Azerbaijan's harmonious interaction between cultures and religions, Abaher El Sakka examines Palestinian sociology from the point of view of knowledge production in the Occupied territories (Chapter 20). He describes an existing rift in the desire to engage in meaningful international collaboration between Palestinians abroad and those working from the inside, when it comes to their views, methods and conceptual issues.

\section{Final remarks:}

\section{New dialogues, new sociologies}

All things considered, the book is a must-read for whoever wishes to reflect on the dilemmas of the development of sociology in the current cultural, political and social context, and on how the process of internationalization of sociology at the local level could be carried respecting local specificities, while at the same time generating new forms of intercultural translation, meaningful in comparative analysis.

At the same time, it brings awareness of how the interpretation local events can actually mirror the very conflicts to which they direct their critique. In Chapter 17, for example, Korczyński and colleagues describe Polish "aversion to 'others'". They first show that the roots of this aversion may lay on the influence of communist dictatorship, which promoted a "'morbid' distrust of others" within the communist bloc. However, the resistance created during the communist domination is currently and sadly directed towards racism and cultural misunderstanding, helped by stereotypes spread by the media, and generated by the current migrant crisis. The authors regret the fact that the stance of Polish sociological community, although sympathetic to the idea of accepting refugees and to the advantages of migration to 
general society, is still more geared to "technocratic and top-down solutions" than to promoting "more common social acceptance and legitimization" (p. 208).

The portraits of local development and institutionalization of sociology and its hurdles in such diverse contexts as Poland, Bangladesh, Palestine, Portugal, Spain, give us the ability to view our own sociological practice with greater awareness and a much wider perspective. With a diversity of perspectives comprised in 21 chapters and 33 authors/organizers from more than 20 different geographical locations, Sociologies in dialogue provides an insight into the multiplicity of areas and questions embraced by sociologists around the world in their pursuit to understand social reality and overcome the challenges connected to both the institutionalization of the discipline in itself and its role in the larger society. It discusses sociological practice and its challenges at all levels - local, international, institutional, and public, pointing to more than one path of growth and improvement for the local and global dialogues in sociology.

\section{References}

HORTON, Richard. COVID-19 is not a pandemic. Comment, The Lancet, v. 396, i.10255, 2020.

NÓBREGA, Rodolfo C. Desigualdades na academia: determinantes para publicação em periódicos de impacto na sociologia. Dissertação (Mestrado, em Sociologia) Programa de Pós-graduação em Sociologia, Universidade de Brasília, 2018.

ZALUAR, Alba; RIBEIRO, Ana Paula Alves. Teoria da eficácia coletiva e violência: o paradoxo do subúrbio carioca. Novos Estudos Cebrap, n. 84, p. 175-196, 2009. 